\title{
Paul Sollie and Marcus Düwell (eds): Evaluating New Technologies. Methodological Problems for the Ethical Assessment of Technology Developments
}

\author{
Springer, The Netherlands, 2009, ISBN 978-90-481-2228-8/e-ISBN \\ 978-90-481-2229-5
}

\section{Neelke Doorn}

Received: 15 June 2009/ Accepted: 24 June 2009/Published online: 14 July 2009

(C) The Author(s) 2009. This article is published with open access at Springerlink.com

Today's society is increasingly shaped around technology. One needs only think of ICT and synthetic biology to see the impact of technology on society. However, due to its large-scale and complex nature, the future consequences of technology are difficult to predict. Hence, decision making about technology is done under conditions of risk and uncertainty. Surprisingly, despite its impact on society, an ethics of technology has emerged only relatively recently. With the volume Evaluating New Technologies. Methodological Problems for the Ethical Assessment of Technology Developments the editors try to contribute to this new branch of ethics.

The book consists of three parts centered around a case study, methodological issues and uncertainty and precaution respectively. The case study concerns the project 'Towards Ultrafast Communication' (TUC), a project funded by the Netherlands Organization for Scientific Research (NWO) and the Technology Foundation STW, which took place between 2003 and 2007. This project was about the development of a prototype optical chip to replace the (relatively slow) electronic chip in communication networks in order to overcome future problems of congestion in data communication and to create faster and more effective use of information and communication networks.

Following the introduction by the editors, the first contribution is by one of the technical researchers of the TUC project. In addition to a brief elaboration of the technics behind the project, the author mentions the ethical and societal aspects of technology development. He argues for an ethical component in technology research. The remaining three chapters in this part are written by ethical researchers or other people with a more reflective stance, some of them closely involved during the project. The contributions differ in the extent to which they are applied to the

\footnotetext{
N. Doorn $(\bowtie)$

Department of Technology, Policy and Management, Delft University of Technology, 3TU. Centre for Ethics and Technology, PO Box 5015, 2600 GA Delft, The Netherlands e-mail: N.Doorn@tudelft.nl
} 
TUC case, which is not necessarily a problem. Especially the contribution by Noëmi Manders-Huits and Jeroen van den Hoven does not extensively discuss the TUC case but provides a more general overview of recent developments in Information Technology and Ethics, with a focus on Value Sensitive Design (VSD). Given the prominence of this concept within the ethics of ICT this chapter forms a valuable contribution in itself. To the other extreme, Anton Vedder and Bart Custers have dedicated a significant amount of text to explaining the TUC project, which comes a bit at the cost of their own message. Contrary to what their title suggests (Whose Responsibility Is It Anyway? Dealing with the Consequences of New Technologies), the authors touch upon the topic of responsibility only briefly, which leaves the reader a bit unsatisfied after finishing this chapter.

The second part is dedicated to the methodological issues of evaluating new technologies. The contribution by Peter-Paul Verbeek discusses the relation between human beings and technology, and its moral implications. He argues that technologies help to shape moral actions and decisions, which calls for a special attention in the design of technological artifacts. For people who still defend the claim that technology is a neutral means, this contribution is a good starting point to become aware of the value-ladenness of technology and technological artifacts. This contribution is followed by a clear analysis of the relation between ethics and empirical science, written by Niels Nijsingh and Marcus Düwell. Similar to, e.g., bioethics, the engineering ethics and ethics of technology increasingly use insights from empirical (social) sciences. Although these insights unmistakably contribute to these branches of applied ethics, it does raise some methodological questions. This contribution is therefore core reading for those ethicists making use of empirical data. The remaining chapters in this part of the book are dedicated to (a critique of) vision management and techno-moral change.

Uncertainty and precaution form the topic of the last part of the book. In the first chapter Paul Sollie provides a thorough analysis of the concept of uncertainty, largely based on (Walker et al. 2003). In this chapter Sollie develops a typology of uncertainty. His concluding outline for 'Any Future Ethics of Technology' is both clear and well argued for. The two following chapters take up the precautionary principle (Steve Clarke) and precautionary reasoning (Dereyk Beyleveld and Roger Brownsword), respectively. These chapters fit nicely in the recent discussions on risk management and its alleged objectivity, and as such they provide an excellent reading for risk analysts and ethicists alike. In the concluding chapter Paul Sollie presents a 'Gewirthian' approach for dealing with complex technology developments under uncertain conditions. In this approach a central role is played by the Principle of Generic Consistency, which requires agents to act in accordance with their own and others' generic rights to freedom and well-being. By applying the approach to some of the questions raised in the previous contributions, this concluding chapter brings (some of) the different contributions in the latter two parts together.

With this last remark we come directly to the major weakness in the book. Although the book contains some excellent contributions, the coherence between the different contributions is sometimes not as strong as it could have been. Especially the first part stands rather loose from parts two ('Methodological issues') 
and three ('Uncertainty and Precaution'). It is only in Chapter 10, a chapter by one of the editors, that reference is made to the TUC project. However, in one of the contributions in the second part extensive reference is made to another case (a hypothetical obesity pill), so the reader might wonder why the authors of this contribution did not apply their framework to the TUC project. Also the layout does not help in that regard. The different authors all use different reference systems (footnotes, endnotes or in the text) which does not contribute to the book's unity.

This being said, with contributions by some prominent authors that work on the interface of Science and Technology Studies (STS) and the ethics of technology and authors interested in more fundamental issues of ethics, the editors have compiled some excellent contributions, notably in the second and third part. Although not all contributions reach this same level of excellence, the book provides sufficient interesting material to make the reader aware of the problems of and possible ways to approach the evaluation of new technologies.

Open Access This article is distributed under the terms of the Creative Commons Attribution Noncommercial License which permits any noncommercial use, distribution, and reproduction in any medium, provided the original author(s) and source are credited.

\section{Reference}

Walker, W. E., Harremoës, P., Rotmans, J., van der Sluis, J. P., van Asselt, M. B. A., Janssen, P., et al. (2003). Defining uncertainty: A conceptual basis for uncertainty management in model-based decision support. Integrated Assessment, 4, 5-17. 